\title{
Methane Number Improvement of Gas from LNG Regasification Unit
}

\author{
Danianto Hendragiri Tjojudo ${ }^{1}$ and Sutrasno Kartohardjono ${ }^{2, *}$ \\ ${ }^{1}$ Department of Procurement for Primary Energy and Business Development, PT Indonesia Power - Kantor Pusat, Jl. Jend. Gatot \\ Subroto Kav 18, Jakarta 12950, Indonesia. \\ ${ }^{2}$ Intensification Process Laboratory, Department of Chemical Engineering Universitas Indonesia, Kampus UI Depok 16424, \\ Indonesia.
}

\begin{abstract}
Methane Number (MN) is one of quality requirement of gas as fuel for gas engine, which indicates fuel capability to avoid knocking in the engine. Higher MN provides better quality of gas for gas engine. Natural gas with higher methane $\left(\mathrm{CH}_{4}\right)$ and fewer higher hydrocarbon, tends to have higher MN score. This study aims to obtain heating methods of LNG to produce vapor that has appropriate $\mathrm{MN}$ as a fuel gas supply to gas engine. The simulation for LNG regasification prepared is an approach to the design of the existing regasification facility of the power plant in Bali. The temperature ranges for LNG heating simulation were obtained based on saturated temperatures of LNG phase envelopes. In the simulation. to obtain a certain MN value can be conducted by adjusting the temperatures at two different values i.e. above $-110{ }^{\circ} \mathrm{C}$ and below - $80{ }^{\circ} \mathrm{C}$. To produce LNG vapor that has $\mathrm{MN}$ of 80 either through higher temperature of heating ( $\mathrm{HT}$ heating) or lower temperature of heating (LT heating) requires more energy than direct heating without MN improvement. Heat loading for LT heating is higher than HT heating due to more temperature defference between LT and heating fluid temperatures. The ability of engine to produce power decreased with decreasing fuel gas $M N$. The power increment increases for lower MN gas if MN improvement is conducted.
\end{abstract}

\section{Introduction}

Liquefied natural gas (LNG) is mainly used in power industry as a fuel gas for gas engine to produce electricity. Utilization of natural gas in the power industry requires quality standards in accordance with the design of the generating machine to produce maximum power. Fuel quality insufficiency refers to the need/design of the generating machine can cause derating, i.e. the decrease in power capable of generating machinery. In a closed combustion engine, a gas engine (reciprocating gas engine), one of the gas quality parameters used is methane number $(\mathrm{MN})$. The $\mathrm{MN}$ is defined as the percentage of methane in a methane/hydrogen mixture which has the same knocking behavior as the gas mixture to be investigated under well-defined testing conditions [1-3]. Knocking in internal combustion engine results from the spontaneous ignition of a portion of the end gas mixture in the combustion chamber ahead of the propagating flame [45]. The range of the minimum $\mathrm{MN}$ required depend on the engine manufacturer. The higher the value of $\mathrm{MN}$ of the fuel gas, the better the gas to be used as fuel in order to avoid knocking (detonation) [6]. One of the effects of the knocking on the engine is the decline in generating power. Pure methane $\left(\mathrm{CH}_{4}\right)$ has a value of $\mathrm{MN} 100$ which shows that as a fuel has the ability to avoid the occurrence of knocking, while Hydrogen $\left(\mathrm{H}_{2}\right)$ pure has a value of MN 0 (zero) which means it is very easy to cause knocking in the machine [7].

One of the gas generating machines used by a power plant in Indonesia requires an optimal MN of 80 . Some brands of gas engines may require $\mathrm{MN}$ values less than 80. In order to obtain gas quality from LNG (liquefied natural gas) with better $\mathrm{MN}$, it is necessary to increase the mole fraction of methane in the gas, which means that the mole fractions of the other components decrease. Increasing the mole fraction of $\mathrm{CH}_{4}$ can be conducted by reducing the number of components other than $\mathrm{CH}_{4}$ or converting other hydrocarbon components i.e. $\mathrm{C} 2 \mathrm{H} 6+$ to $\mathrm{CH}_{4}$. This study aims to obtain an alternative method of improving gas composition to attain an appropriate MN as a fuel gas supply to gas engine.

\section{Methods}

The LNG regasification gas quality data used in this study were taken from data owned by one of power plants which operate Power Plant Gas Diesel Engine (PLTDG) in Bali. The data used were the sampling of gas quality data from LNG regasification in the period of January to August 2017. Analyses of hydrocarbon components in LNG was based on the LNG main component i.e. $\mathrm{CH}_{4}, \mathrm{C} 2 \mathrm{H} 6$ (ethane) and $\mathrm{C} 3 \mathrm{H} 8$ (propane) as the ratio of these components has an effect on MN value of the fuel gas. The simulation for LNG

Corresponding author: sutrasno@che.ui.ac.id 
regasification prepared is an approach to the design of the regasification facility of the power plant in Bali. This approach was conducted due to the limited access to the design facility in relation to the facility design copyright. The main method of regasification used was heating using hot water/steam from a gas-fired boiler. The simulation referred to the gas composition to the plant with the lowest heating value ever used by the gas engine and the maximum quantity of gas output required by the engine.

\section{Results and Discussion}

This study used six data samples of natural gas composition having MN below 80. The natural gas data conditions, related to the composition and results of $\mathrm{MN}$ calculations are shown in Table 1. Based on the data on Table 1, there is a relationship between the value of the $\mathrm{CH}_{4}$ composition to the $\mathrm{MN}$ values as shown in Fig. 1, where the higher the $\mathrm{CH}_{4}$ mole fraction in a natural gas mixture the higher the value of the MN.

The LNG compositions for the simulation were calculated based on the natural gas and boil off gas (BOG) flowrates and compositions. The results were summarized in Table 2.

Table 1. Gas data conditions.

\begin{tabular}{|c|c|c|c|c|c|c|}
\hline \multirow{2}{*}{$\begin{array}{c}\text { Compo- } \\
\text { nent }\end{array}$} & \multicolumn{6}{|c|}{ Composition (mole fraction) } \\
\hline & $\begin{array}{c}\text { Sample } \\
1\end{array}$ & $\begin{array}{c}\text { Sample } \\
\mathbf{2}\end{array}$ & $\begin{array}{c}\text { Sample } \\
\mathbf{3}\end{array}$ & $\begin{array}{c}\text { Sample } \\
4\end{array}$ & $\begin{array}{c}\text { Sample } \\
5\end{array}$ & $\begin{array}{c}\text { Sample } \\
6\end{array}$ \\
\hline Methane & 0.8742 & 0.8841 & 0.9087 & 0.9192 & 0.9317 & 0.9403 \\
\hline Ethane & 0.0683 & 0.0631 & 0.0427 & 0.0377 & 0.0350 & 0.0325 \\
\hline Prophane & 0.0403 & 0.0370 & 0.0334 & 0.0299 & 0.0223 & 0.0189 \\
\hline i-Butane & 0.0082 & 0.0075 & 0.0066 & 0.0058 & 0.0050 & 0.0039 \\
\hline n-Butane & 0.0088 & 0.0081 & 0.0082 & 0.0070 & 0.0058 & 0.0041 \\
\hline i-Pentane & 0.0001 & 0.0001 & 0.0002 & 0.0002 & 0.0001 & 0.0001 \\
\hline n-Pentane & 0.0000 & 0.0000 & 0.0000 & 0.0000 & 0.0000 & 0.0000 \\
\hline $\mathrm{C} 6+$ & 0.0000 & 0.0000 & 0.0000 & 0.0000 & 0.0000 & 0.0000 \\
\hline $\mathrm{CO} 2$ & 0.0000 & 0.0000 & 0.0000 & 0.0000 & 0.0000 & 0.0000 \\
\hline Nitrogen & 0.0002 & 0.0002 & 0.0002 & 0.0002 & 0.0002 & 0.0002 \\
\hline $\mathrm{H} 2 \mathrm{O}$ & 0.0000 & 0.0000 & 0.0000 & 0.0000 & 0.0000 & 0.0000 \\
\hline H/C Ratio & 3.67 & 3.69 & 3.73 & 3.76 & 3.80 & 3.83 \\
\hline MN & 66.64 & 68.25 & 71.55 & 73.82 & 77.20 & 79.90 \\
\hline
\end{tabular}

The phase characteristics of LNG compositions are presented in Fig. 2., and Fig. 3., where under the same pressure conditions, the LNG with higher $\mathrm{CH} 4$ composition tend to have temperature range of two phases in the envelope more narrow than LNG with lower $\mathrm{CH} 4$ composition. These range of temperatures differences are very useful in controlling regasification temperature to remove $\mathrm{CH} 4$ from higher hydrocarbons in
LNG regasification in order to increase the $\mathrm{MN}$ value. The LNG regasifications were simulated based on direct LNG regasification and $\mathrm{LNG}$ regasification for $\mathrm{MN}$ improvement. Direct LNG regasification is the process of regasification of LNG through one stage of heating to a required temperature and pressure of $25 \square$ and 8.5 bar, respectively, using heating steam at temperature and pressure of $180 \square$ and pressure 5 bar, respectively, as shown in Fig. 4. Meanwhile, the LNG regasification for MN improvement is conducted through two stages of heating as shown in Fig. 5.

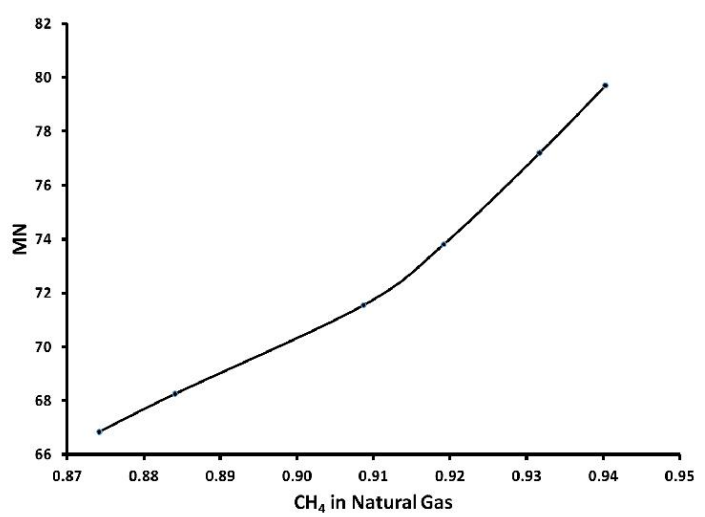

Fig. 1. The effect of $\mathrm{CH}_{4}$ composition in natural gas on the value of $\mathrm{MN}$.

Table 2. LNG compositions.

\begin{tabular}{|l|l|l|l|l|l|l|}
\hline \multirow{2}{*}{ Component } & \multicolumn{5}{|c|}{ Compositions (mole fraction) } \\
\cline { 2 - 7 } & LNG 1 & LNG 2 & LNG 3 & LNG 4 & LNG 5 & LNG 6 \\
\hline Methane & 0.8722 & 0.8822 & 0.9072 & 0.9179 & 0.9306 & 0.9394 \\
\hline Ethane & 0.0694 & 0.0642 & 0.0434 & 0.0383 & 0.0356 & 0.0331 \\
\hline propane & 0.0410 & 0.0377 & 0.0339 & 0.0304 & 0.0227 & 0.0192 \\
\hline i-Butane & 0.0083 & 0.0076 & 0.0068 & 0.0059 & 0.0051 & 0.0039 \\
\hline n-Butane & 0.0090 & 0.0082 & 0.0083 & 0.0072 & 0.0059 & 0.0042 \\
\hline i-Pentane & 0.0001 & 0.0001 & 0.0002 & 0.0002 & 0.0001 & 0.0001 \\
\hline n-Pentane & 0.0000 & 0.0000 & 0.0000 & 0.0000 & 0.0000 & 0.0000 \\
\hline C6+ & 0.0000 & 0.0000 & 0.0000 & 0.0000 & 0.0000 & 0.0000 \\
\hline CO2 & 0.0000 & 0.0000 & 0.0000 & 0.0000 & 0.0000 & 0.0000 \\
\hline Nitrogen & 0.0001 & 0.0001 & 0.0001 & 0.0001 & 0.0001 & 0.0001 \\
\hline H20 & 0.0000 & 0.0000 & 0.0000 & 0.0000 & 0.0000 & 0.0000 \\
\hline
\end{tabular}

Fig. 6 shows the effect of $\mathrm{CH}_{4}$ composition in LNG on the heat loading for heating of 50 MMSCFD LNG. The heat loading decreased with increasing the $\mathrm{CH}_{4}$ composition in LNG due to the lower heat flow of LNG with higher $\mathrm{CH}_{4}$ composition. To obtain a better $\mathrm{MN}$ value from $\mathrm{LNG}$ composition, $\mathrm{CH}_{4}$ was separated from its mixture in LNG and then was used as the gas delivered to the primary use so that the gas content has more suitable $\mathrm{CH}_{4}$ mole fraction. The separation process is conducted by gradually heating of LNG as shown in Fig. 5., where LNG is preheated in HX $1 \mathrm{Sp}$ and HX 2 Sp heat exchanger at temperature causing 2 (two) phase conditions i.e. liquid and vapor. The liquid phase is

\footnotetext{
Corresponding author: sutrasno@che.ui.ac.id
} 
dominated by $\mathrm{C}_{2} \mathrm{H}_{6}$ and heavier hydrocarbons. After this separation process. $\mathrm{CH}_{4}$-rich gas can be prioritized for distribution to users/plants after mixed with BOG. Meanwhile. $\mathrm{C}_{2} \mathrm{H}_{6}$-rich and heavier hydrocarbons can be used as gases for heating/steam heat. If there is a lack of energy for the heater, the shortage can be taken from the gas supplied to the plant. However, if the use of Gas Heaters is not as large as the available amount, then the rest can be distributed to the plant and mixed with $\mathrm{CH}_{4}$ and $\mathrm{BOG}$ rich gas.

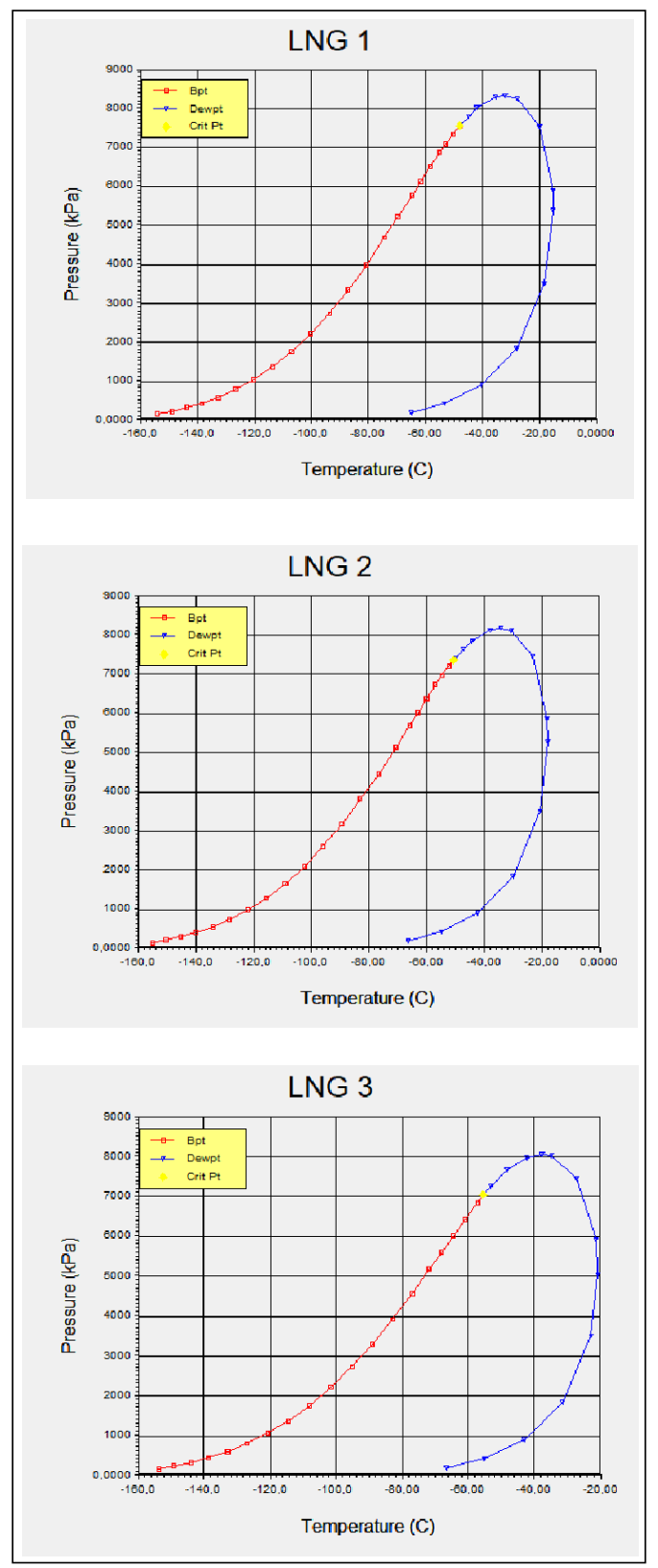

Fig. 2. The LNG phase envelope characteristics LNG $1-3$.

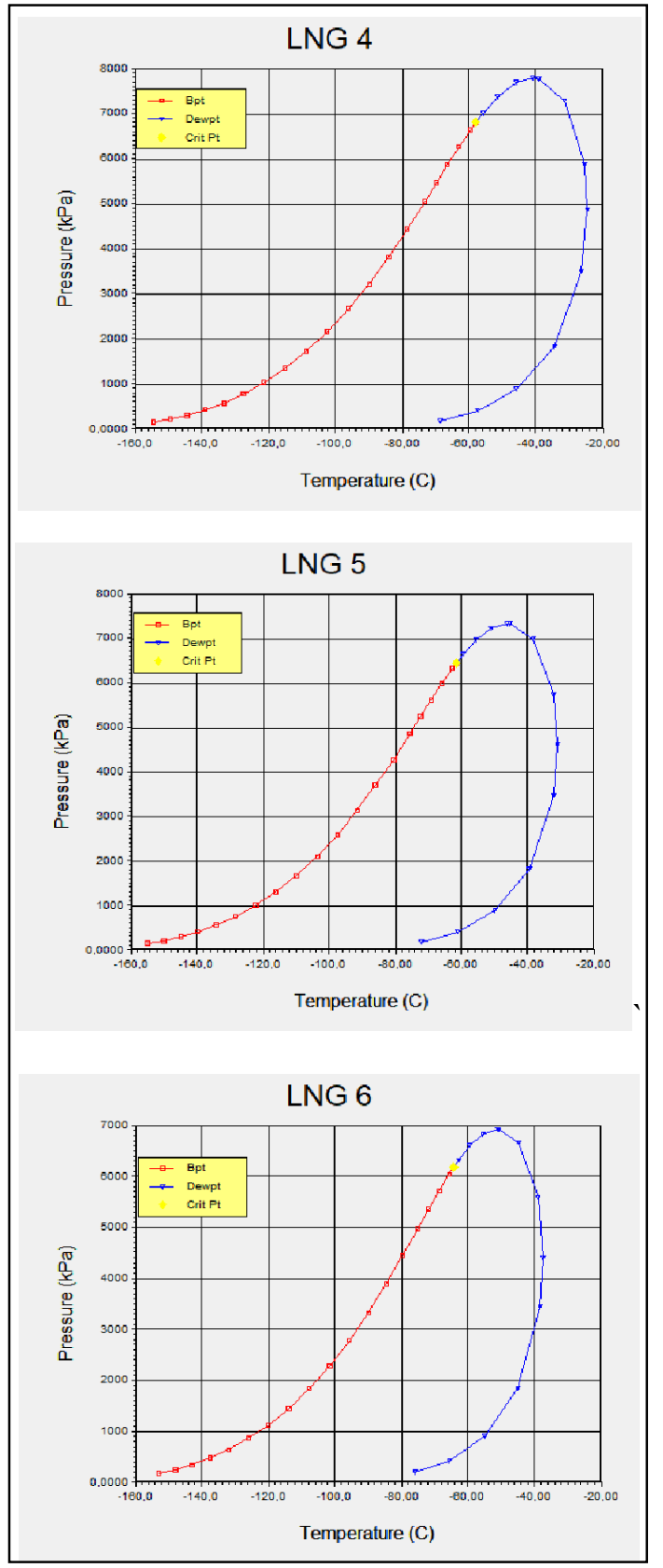

Fig. 3. The LNG phase envelope characteristics LNG 4-6.

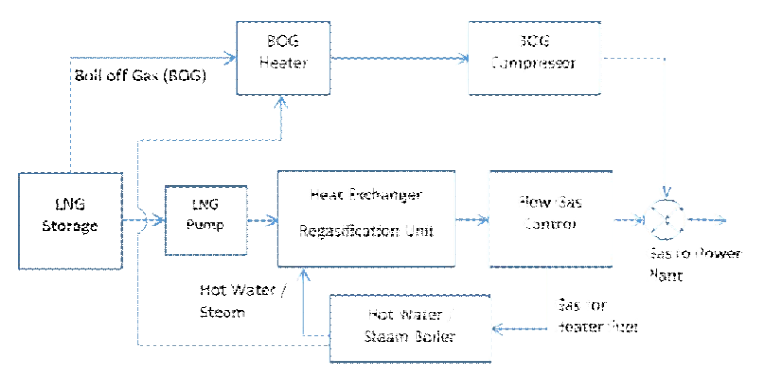

Fig. 4. Block diagram direct $L N G$ regasification 


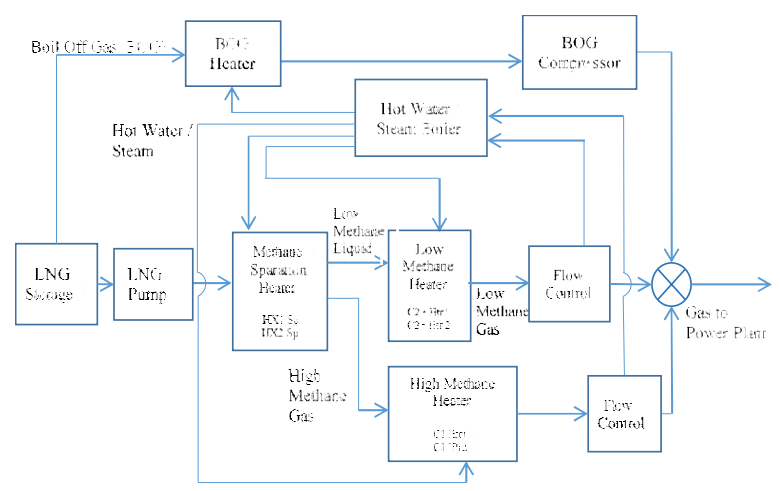

Fig. 5. Block diagram of $\mathrm{LNG}$ regasification for $\mathrm{MN}$ improvement.

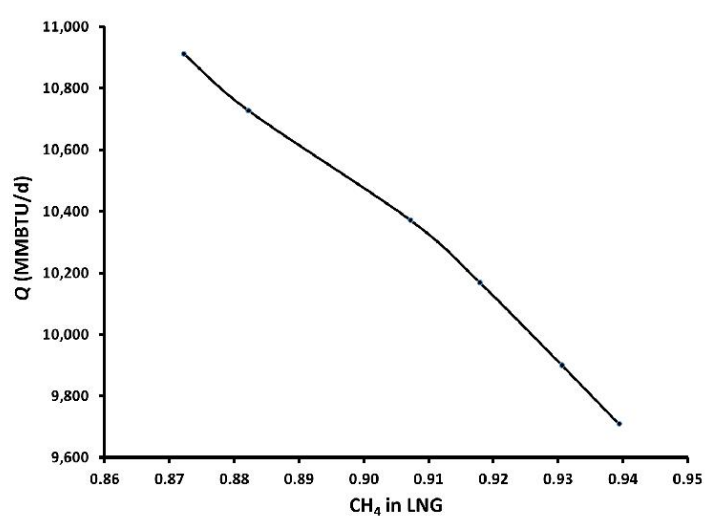

Fig. 6. The effect of $\mathrm{CH}_{4}$ composition in $\mathrm{LNG}$ on the heat loding for heating. $Q$.

In the simulation, the target to be achieved is to find the composition and $\mathrm{MN}$ of the gas delivered to the plant according to the required temperature and pressure of 25 ${ }^{\circ} \mathrm{C}$ and 8.5 bar, respectively. Therefore, the working pressure on the heat exchanger and $\mathrm{BOG}$ is at 8.5 bar, and each LNG is processed as follows:

1. To adjust the output temperature of LNG in the $\mathrm{HX}_{1}$ $\mathrm{Sp}$ and $\mathrm{HX}_{2} \mathrm{Sp}$ heat exchanger according to:

a. Minimum Simulation is to set the output temperature at the value less/close to the condition of temperature cross on the heat exchanger C1 Htr1 Sp and C1 Htr2 Sp. Both heat exchangers serve to increase the temperature of the $\mathrm{CH}_{4}$-rich gas in the $\mathrm{HX}_{1} \mathrm{Sp}$ and $\mathrm{HX}_{2} \mathrm{Sp}$ heat exchangers. Temperature Cross is a condition in which the heating fluid and the heated fluid are at the same temperature before the expected temperature of the fluid coming out of the heat exchanger is reached.

b. Maximum Simulation is to set the temperature less/close to the condition of temperature cross on heat exchanger $\mathrm{C} 2+\mathrm{Htr} 1 \mathrm{Sp}$ and $\mathrm{C} 2+\mathrm{Htr} 2$ Sp. Both heat exchangers are the heater for the material stream dominated by $\mathrm{C} 2 \mathrm{H} 6$ and heavier hydrocarbons produced from the previous process. c. Simulation MN 80 is a simulation with output temperature from HX1 Sp and HX2 Sp heat

2. To set the temperatures of gas out of High Methane Heater, so as the temperature of Gas to Power Plant is $25^{\circ} \mathrm{C}$.

The simulation results of the steps were the temperature range for further simulation to find the $\mathrm{MN}$ of each samples as shown in Fig. 7. The different in temperature range of each samples also give different MN number, but have similar type of trend as demonstrated in Fig. 8. In the simulation, it was shown that to obtain a certain $\mathrm{MN}$ value can be conducted by adjusting the temperatures at two different values. With respect to each sample studied, there are two control temperatures can be applied to obtain $\mathrm{MN}$ of 80 i.e. above $-110^{\circ} \mathrm{C}$ and below $-80^{\circ} \mathrm{C}$ as shown in Fig. 8 for LNG sample 1. However, the temperature range of heating cannot produce vapor which has MN of 100 , even though the heating temperature was below the evaporation temperature of $\mathrm{C}_{2} \mathrm{H}_{6}$.

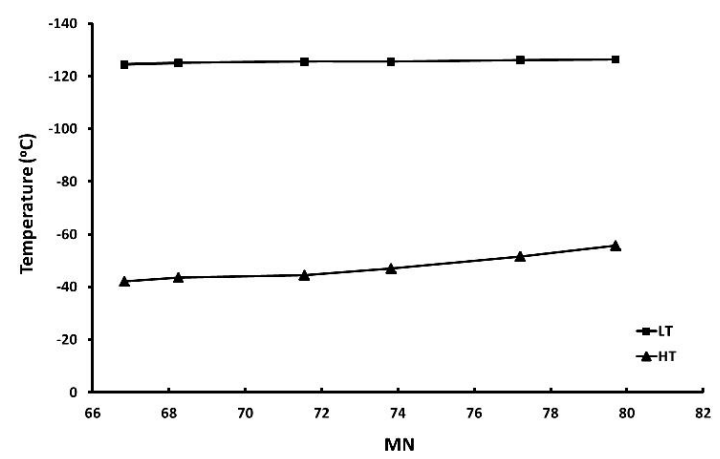

Fig. 7. The range of higher and lower temperatures for obtaining MN simulation.

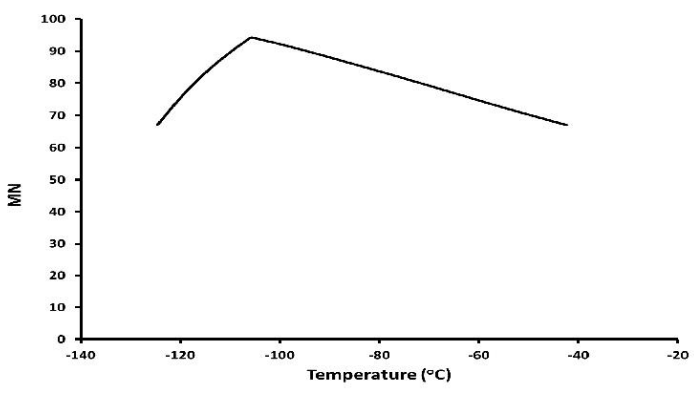

Fig. 8. The MN values as a function of heating temperatures for LNG sample 1.

The heat loading to produce LNG vapor that has MN of 80 in the heat exchangers for lower and higher temperatures of heating are demonstrated in Fig. 9. It is illustrated that to produce $\mathrm{LNG}$ vapor that has $\mathrm{MN}$ of 80 either through higher temperature of heating (HT heating) or lower temperature of heating (LT heating) requires more heating energy than direct heating without MN improvement. Heat loading for LT heating is higher than HT heating due to more temperature difference

\footnotetext{
Corresponding author: sutrasno@,che.ui.ac.id
} 
between LT and heating fluid temperatures as shown in Fig. 9.

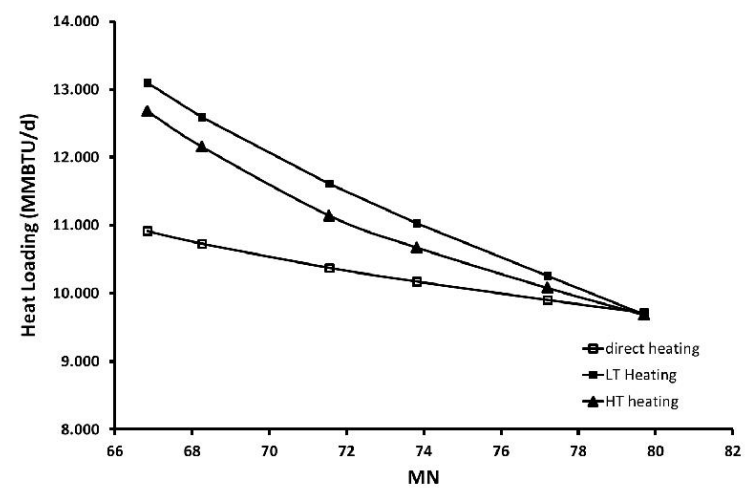

Fig. 9. The heat loading for direct, LT and HT heatings as a function of $\mathrm{MN}$ of LNG.

The influence of MN on engine capability was approached by assuming that the gas engine has a maximum capability when using fuel gas with minimum $\mathrm{MN}$ at 80 . The power produced by the engine decreased with decreasing gas $\mathrm{MN}$ as shown in Fig. 10. On the other hand, if the MN improvement is conducted to the gas, the power increment increased with decreasing MN. Furthermore, the decrease in the power produced will increase the fuel gas consumption in the gas engine.

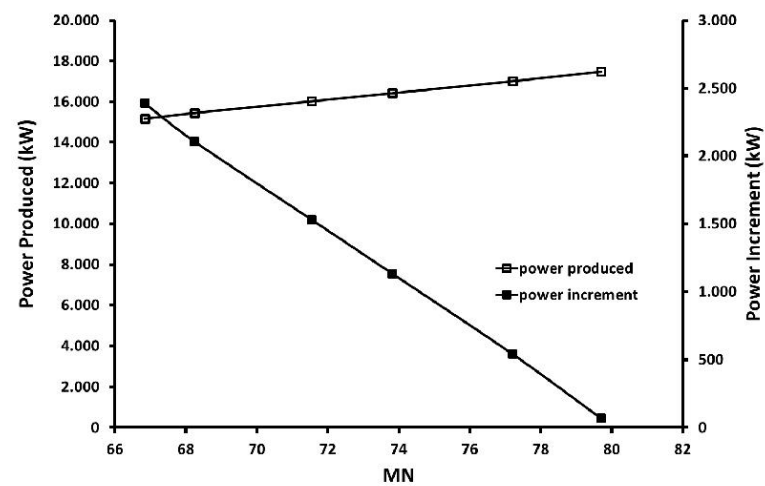

Fig. 10. The power produced by the gas engine and power increment as a function of MN of LNG.

\section{Conclusions}

The value of MN of fuel gas is very importance in producing power in gas engine. Generally, gas engine requires $\mathrm{MN}$ value of minimum 80 has to be fulfilled in MN quality to produce maximum power. Therefore, there is a need to improve MN from the fuel gas if its $\mathrm{MN}$ value is far from 80. In LNG regasification, the evaporation can be conducted at lower temperature or higher temperature to produce gas at $\mathrm{MN}$ of 80 . To produce gas at MN of 80 from the LNG samples in this study can be conducted at the temperature above $-110 \square$ or below $-80 \square$. In the LNG regasification, the heat needed to produce MN vapor of 80 increased with decreasing $\mathrm{MN}$ of $\mathrm{LNG}$. There was more heat required for lower temperature evaporation than higher temperature evaporation due the temperature different between heating temperature and heating fluid temperature. The ability of engine to produce power decreased with decreasing fuel gas MN. Therefore, the power increment increases for lower $\mathrm{MN}$ gas if $\mathrm{MN}$ improvement is conducted.

The authors are grateful to the support from the National Electric Company in cooperation with Faculty of Engineering Universitas Indonesia through Contract No . 1212I.Pj/HKM.00.01/DIR/2016.

\section{References}

1. B. Gieseking and A. S. Brown. Fuel. 185. 932-940 (2016).

2. P. S. Roy, C. Ryu, and C. S. Park. Fuel. 224. 121127 (2018)

3. D. Puente, F. J. Gracia, and I. Ayerdi. Sens. and Act. B: Chem. 110. 181-189 (2005).

4. S. Szwaja. K.R. Bhandary. J.D. Naber. J. Hy. En. 32. 5076-5087 (2007).

5. M. Malenshek and D. B. Olsen. Fuel. 88. 650-656 (2009).

6. K. Saikaly, O. Le Corre, C. Rahmouni, and L. Truffet. Fuel Proc. Tech. 91, 641-652 (2010).

7. J. P. Gómez Montoya, A. A. Amell, and D. B. Olsen. Fuel. 186. 168-175 (2016).

\footnotetext{
Corresponding author: sutrasno@che.ui.ac.id
} 